value of straw for livestock feed, 71 genotypes of lentil were evaluated for straw fodder quality and their potential trade-offs with straw and grain yield. Straw fodder quality traits chosen were crude protein, invitro digestibility and in-vitro metabolisable energy content, analyzed using a combination of conventional laboratory techniques and Near Infrared Reflectance Spectroscopy (NIRS). Results from eight trials across three sites using randomized complete block design showed highly significant genotypic variation in grain and straw yields as well as in straw fodder quality traits. A positive correlation between grain yield and straw yield was observed $(\mathrm{r}=0.55, \mathrm{P}<0.01)$. The correlation between crude protein of the straw and grain yield was strong and negative $(\mathrm{r}=-0.73 ; \mathrm{P}<0.01)$, the correlations were weak and negative between grain yield and total in-vitro organic matter digestibility $(\mathrm{r}=-0.12$; $\mathrm{P}<0.01)$ and between grain yield and metabolisable energy $\mathrm{ME}(\mathrm{r}=-0.03 ; \mathrm{P}>0.05)$. Crude protein can, therefore, be considered as an important criteria for varietal selection for food-feed traits. The study pinpoints to the possibility of incorporating straw traits to generate food-feed varieties of lentil to address the high demand for grain and livestock fodder in the mixed crop-livestock farming system of Ethiopia.

\title{
PP151: Variation in the straw traits of morphological fractions of faba bean and implications for selecting for food-feed varieties
}

\author{
Ashraf Alkhtib*, Jane Wamatu, Teklu Wegi, and Barbara Rischkowsky \\ International Center of Agricultural Research in the Dry Areas (ICARDA), Addis Ababa, Ethiopia. \\ *a.alkhtib@cgiar.org)
}

Five varieties of faba bean (four improved released varieties and one local variety) were investigated for varietal variation in straw yield, nutritive value of straw morphological fractions and grain yield. Samples of the whole plant biomass were collected and separated into grain and straw. The straw was further divided into leaves, stems and pods. Straw samples were analyzed for their chemical composition (CP, NDF, ADF, ADL, TIVOMD) and ME. The PUI was employed to rank the varieties. The results demonstrated significant varietal variation in grain yield, straw yield and in the proportions of botanical fractions of straw, grain yield and straw yield. The improved varieties were superior to the local variety in grain yield, straw yield and PUI. The local variety had the highest proportion of stem and the lowest proportion of leaf and pods. Significant varietal differences $(\mathrm{P}<0.001)$ were detected in TIVOMD, ME, NDF, ADF and ADL of whole straw. The leaves showed the highest TIVOMD and content of CP, while pods were highest in ME. Canonical correlation analysis showed significant $(\mathrm{P}<0.001)$ correlations between the nutritive value of the whole straw and the nutritive value and proportions of its botanical fractions. Grain and straw yields were positively, strongly and significantly $(\mathrm{P}<0.001)$ correlated. Weak correlations were detected between the grain yield and straw quality traits. Ranking the varieties differed when the grain yield, straw quality scores and PUI were considered. However the weak correlation existed between straw quality, including straw quality index or PUI to select food-feed varieties of faba bean. These findings indicate the possibility of selecting faba bean varieties which combine superior grain and straw traits.

\section{PP152: Lentil seed quality as influenced by environmental factors}

Renuka Shrestha*, Shiv Kumar, Albert Vandenberg, Ashutosh Sarker, Rajendra Darai and Dhan Bahadur Gharti

Nepal Agricultural Research Council, Nepal; International Center for Agricultural Research in the Dry Areas (ICARDA), Rabat, Morocco.*(renuka.shrestha@gmail.com)

Field experiments consisting of eighteen lentil genotypes were evaluated at research stations under Nepal Agricultural Research Council located at varied agro-ecological zones with the elevation ranging from 